\title{
Arte pública: a educação, 0 cotidiano, a reinvenção
}

TAMIRIS VAZ

VIVIANE DIEHL

\section{Resumo}

Apresento neste artigo uma pesquisa referente ao trabalho de conclusão do curso de Licenciatura em Artes Visuais, na Universidade Federal de Santa Maria, onde promovo um diálogo acerca da arte pública, de sua abordagem no contexto da arte e educação e das possibilidades de reinvenções de si e dos espaços cotidianos. Para isso, realizo entrevistas semi-estruturadas com um educando, um artista e dois professores que experienciaram produções em arte pública, em uma análise temática, onde os colaboradores relatam sua preocupação quanto ao papel da arte pública na sociedade atual e suas implicações para o âmbito educacional.

Palavras-chave: Arte pública, educação, espaços cotidianos 


\section{Public art: education, quotidian, reinvention}

TAMIRIS VAZ

VIVIANE DIEHL

\section{Abstract}

This article presents a research which refers to my conclusion work to the Visual Arts Teaching graduation at Federal University of Santa Maria, where I promote a dialog about public art, its approach into the art education context and into the possibilities of reinventions of the self and of the daily spaces. For that, I conduct semi-structured interviews with a student, an artist and two teachers who experienced productions on public art. It's done at a thematic analysis, where the collaborators report their concerns about the role of public art at society nowadays and its educational consequences. 
Este texto é uma síntese do trabalho de conclusão do curso de Artes Visuais - Licenciatura Plena em Desenho e Plástica que realizei no primeiro semestre de 2010, onde, com o título "Espaço Cotidiano e Educação: a arte pública na reinvenção de lugares e pessoas”, teço algumas reflexões acerca da docência em artes visuais, dialogando sobre as possibilidades do uso da arte pública como ponto de interseção entre educação, arte e cotidiano.

Ao iniciar meu trabalho como educadora em artes visuais pensei, desde o primeiro de quatro semestres de estágios supervisionados, na relação dos educandos com seus espaços cotidianos, considerando o termo "lugar comum", com o qual problematizo os modos como diferentes indivíduos podem se relacionar com os mesmos espaços de convívio, além de traçar estratégias de reinvenção de tais lugares, atuando dentro e a partir deles para trabalhar singularidades dos estudantes a partir de temáticas cotidianas.

Tais questões me levam ao encontro com a arte pública, complementado pela criação do coletivo de ações artísticas (Des) esperar ${ }^{1}$, onde atuo junto a outros três artistas, o que me motiva a dar continuidade a essa pesquisa, refletindo sobre o que constitui, hoje, a arte pública e quais as possibilidades surgidas a partir de uma maior integração da mesma no cotidiano escolar quando encaminhada para a ressignificação de espaços.

Partindo de entrevistas realizadas com quatro pessoas que carregam, em suas trajetórias, diversas relações com a arte pública, dialogo com um artista, dois professores de artes visuais e uma estudante da Educação Básica, objetivando perceber as relações manifestas em suas aproximações com a arte pública e como essas experiências são vistas quando utilizadas como possibilidade de ensino e aprendizagem. Assim, busco possíveis respostas para o problema: Quando a arte pública pode se constituir 
em possibilidades de atuação e ressignificação do espaço cotidiano e de que modo interfere no contexto educativo?

\section{O lugar da arte pública na sociedade atual}

Desde o mundo antigo a arte pública era usada como símbolo de poder, estratégia de marketing para afirmar forças políticas através da inserção de monumentos em espaços abertos. Obras de arte como demarcação política, ou para situar eventos comemorativos através do embelezamento da cidade, foram utilizadas, indiscutivelmente, como único sinônimo de arte pública mais ou menos até o início do século XX, quando emergiu uma discussão sobre a dissociação dessas obras com o ambiente que as acolhe, pois estas normalmente eram construídas em ateliês e colocadas no espaço das ruas, muitas vezes sem que fossem projetadas para esses locais específicos, destoando do cotidiano da população (SILVA, 2005).

Em meados dos anos 1960, surgem movimentos artísticos que visam promover rupturas na arte pública oficial. Segundo Silva (2005), algumas manifestações político-estéticas realizadas nessa década por artistas como Artur Barrio e Cildo Meireles, além de propor uma forma participativa de arte pública, "também serviam como manifestações de protesto contra a opressão, a perseguição política, a censura e a falta de liberdade de expressão no Brasil, durante a ditadura militar" (2005, p.86).

Com essas discussões, surgem questionamentos sobre o papel e a atuação social de instituições artísticas como museus e galerias. A obra, antes facilmente identificada pela sua colocação em um espaço próprio e delimitada por uma moldura ou pedestal, hoje se expande de uma maneira que, por vezes, nem há como separar público-obra-criador, ao passo que uma obra pode existir até mesmo quando não constituída de matéria, como no caso da 'arte conceitual'. Surge o grafite como uma expressão artística subversiva que, essencialmente, povoa a cidade sem se preocupar com avais curatoriais, mas que aos poucos também vai sendo inserida no circuito institucional, saindo da clandestinidade e adentrando lugares legitimadores. Exige-se, assim, a negociação de espaços, o que se produz na rua de repente é encontrado nas paredes do museu, ao mesmo tempo em que a própria cidade é levada a ser percebida como espaço de produção artística.

A clássica distinção entre arte pública e arte privada torna-se difusa, pois o fato de uma obra estar em um espaço de circulação de pessoas não é pré-requisito para que seja 
entendida como pública; constantemente ela corre o risco de estar invadindo este espaço e forçando indivíduos a aceitá-la e incorporá-la em seu cotidiano. Nesse sentido, não compreendemos uma obra como pública somente pelo fato de estar em local de livre acesso, pois uma presença impositiva e descontextualizada poderia torná-la tão excludente quanto se estivesse em um espaço elitizado de acesso restrito. Para ser pública, tem que ser acessível ao público, não precisa necessariamente resolver os problemas estruturais de uma cidade, mas é importante que quem produz esteja ciente das questões presentes naquele lugar, não no sentido de adequar o trabalho artístico a questões já explícitas, mas de fazê-lo um componente adicional da paisagem, seja por reforçar algo implícito ou por se opor a algo já existente.

A arte da rua que se desloca para o museu, como no caso do grafite, não consegue deslocar para junto de si o contexto urbano no qual fora instalada, as questões presentes no espaço da rua não serão as mesmas encontradas no espaço do museu. Com esse deslocamento, a obra não só pode perder seu sentido político em detrimento de valores estéticos como também pode incitar outros sentidos jamais imaginados quando não isolada na pretensa neutralidade dos espaços expositivos.

Produzir arte pública, dentro do que é apresentado neste texto, é produzir algo capaz de transformar um local em lugar; um 'lugar-comum', espaço banalizado, em 'lugar comum', espaço coletivo, mas propiciador de descobertas individuais, motivadas pelas disposições culturais do espectador.

\section{Espaço e cotidiano}

Foucault (1967) escreve que, muito mais que o tempo, o espaço é um fator fundamental como motivador da ansiedade de nossa época. Isso porque vivemos uma situação onde "a nossa experiência do mundo se assemelha mais a uma rede que vai ligando pontos e se intersecta com a sua própria meada do que propriamente a uma vivência que se vai enriquecendo com o tempo" (FOUCAULT, 1967). Desse modo, o espaço nos amplia possibilidades de justaposições, de fugir da sistematização cronológica que o tempo impõe à criação, pois, nas produções artísticas contemporâneas, já não há um novo que sucede e supera o antigo; a multiplicidade de linguagens e hibridações ultrapassa modos lineares de representação.

Para melhor compreender o conceito de espaço, considero duas outras derivações, descritas por Carvalho (2007) 
como "local e lugar", onde enprega-se a primeira para delimitar os aspectos de ordem física, materiais e mensuráveis, constituintes da experiência espacial, e a segunda para os de ordem simbólica, cultural, não mensuráveis em termos quantitativos rigorosos. Assim, o local estaria mais ligado ao sentido de localização, endereço físico, geográfico, enquanto o lugar engloba subjetividades formadas a partir de vivências que dão ao espaço significados mais particulares à forma como se faz uso dele. No caso desta pesquisa busca-se, através da arte pública, pensar o espaço cotidiano como lugar, restaurando nele significados ignorados ou recriando sentidos que façam de um simples local um lugar de experiências instigadoras do olhar.

Aquilo que compreendo, percebo a partir de mim e da minha relação com experiências anteriores que subsidiaram as possibilidades de interpretação do que vejo. Com isso, o que compreendo do objeto diz muito do que ele é, mas muito mais do que eu sou, do que existe em mim para compreendê-lo. Por isso nos diz Peixoto (2003) que

olhar um objeto é mergulhar nele. Os objetos circundantes tornam-se horizonte, a visão é um ato de dois lados. Ou seja: ver um objeto é ir habitá-lo e daí observar todas as coisas. Mas, como também nelas estou virtualmente situado, tomo de diferentes ângulos o objeto principal de minha observação. (PEIXOTO, 2003, p.177)

Essa concepção da submersão ao objeto, que neste caso colocamos como a presença da arte pública, ganha outro enfoque do ponto de vista de Saramago (2003) em "O Conto da Ilha Desconhecida", onde ele descreve a história de um homem que, de forma desmedida, bate à porta do rei para solicitar-lhe um barco. Sua intenção, ele explica, é a de procurar uma ilha desconhecida. Não há ninguém que acredite ainda haver ilhas desconhecidas, pois os mapas já reproduzem todos os lugares existentes. No entanto, o homem diz que uma ilha desconhecida não poderia estar no mapa, já que ninguém ainda soubera sobre sua existência. Ele explica "que é necessário sair da ilha para ver a ilha, que não nos vemos se não nos saímos de nós" (SARAMAGO, 2003, p.41). Nesse caso, não se mergulha em um objeto para percebê-lo, mas pelo contrário, não se o percebe por estar nele imerso, é preciso "sair da ilha para ver a ilha", é preciso sair de mim 
para conhecer a mim mesmo, mudar o ângulo de visão para que a rotina não torne a paisagem invisível.

A reação aos estímulos estéticos aparece ligada aos hábitos enraizados na sensibilidade de quem os percebe sendo, então, o significado multiforme. Assim, ao passo que nossas experiências vão se modificando, podemos retornar à mesma mensagem e compreendê-la de outro ponto de vista. Parafraseando Saramago (2003), é preciso um constante ir e vir da ilha para que não a esqueçamos, para que voltemos a habitá-la. Sobre esse retorno à experiência, Eco (2003, p.85) diz que os significados

já de início serão diferentes dos que foram realizados no primeiro contato, pois a complexidade do estímulo terá permitido automaticamente que a nova percepção se dê segundo uma perspectiva diferente, segundo uma nova hierarquia dos estímulos. (ECO, 2033, P.85)

Dialogar sobre o próprio lugar e a ocupação dos espaços cotidianos é uma possibilidade de potencializar criações além do lugar-comum anulado pela banalização do olhar, podendo, então, buscar a reinvenção de lugares a partir de si e das percepções coletivas e individuais do mundo. É neste ponto que se insere a educação, ao propiciar, nas aulas de artes visuais, experimentações que extrapolem as visões das paisagens como lugares inertes, fazendo do espaço cotidiano laboratório de invenções de si.

Ao abordar os espaços cotidianos enquanto local para experimentações, penso nesses lugares como palimpsestos, já dotados de cargas simbólicas, de memórias coletivas que constituem sentidos, que nomeiam esses espaços e os tornam lugares comuns. Significados que vão criando vida, ao passo que acumulam em si todas as experiências humanas e modificações ocorridas ao longo do tempo. Doberti (2009) aponta a memória da cidade como uma presença dinâmica onde, a cada momento se interferem discursos, imagens e lugares, uns sobre os outros. Tudo aquilo que se incorpora, modifica seu âmbito de origem, e fala, assim, da presença dos artistas na rua:

Podemos decir entonces que la memoria urbana es un palimpsesto y que los artistas callejeros recuperan las huellas de la ciudad para dejar sus propias marcas, invitando a los transeúntes a sumar también sus rastros, a la manera de un eco colectivo, de un estallido de imágenes. (DOBERTI, 2009, p.4) 
Dialogar sobre essas percepções pode auxiliar na compreensão do quebra-cabeça que compõe as paisagens, no sentido de ampliar o ângulo de visão, de perceber de pontos de vista diferentes um mesmo acontecimento. Um espaço público não é aquele espaço que se apresenta redundantemente o mesmo para todas as pessoas, ele só é público por propiciar singulares relações por cada indivíduo que nele vive. O espaço de todos é a sociedade de consumo que padroniza necessidades, é o espaço dos vendedores ambulantes que disputam o melhor canto para promover suas vendas, é o gato que ignora tudo ao redor para correr atrás da borboleta, é a moça que paralisa diante de uma vitrine e se incomoda com os gritos dos estudantes que protestam com faixas e cartazes contra o aumento da passagem e atropelam a borboleta que fugia do gato. O espaço de todos se transforma à medida em que nele são tecidas relações cotidianas; cada pessoa o percebe e o inventa de maneiras diferentes e cada nova invenção implica em mudanças nas vivências coletivas, nos modos como o fluxo cotidiano acontece.

Partindo do exposto, podemos pensar naquilo que Augé (apud Canton, 2009) chama de 'não lugar' na organização urbana. São aqueles locais pelos quais passamos a todo o momento, mas que ignoramos por não nos servirem como espaços habitáveis, lugares para os quais pouco se olha, "lugares de passagem, lugares virtuais, lugares que nos impõem outro tipo de troca" (CANTON, 2009, p.58). As pessoas se deslocam com muita rapidez, e esses lugares de movimento, de não permanência dessituam a antiga função dos espaços, onde a própria moradia se torna um local de transição entre a noite e o amanhecer para que se reinicie a acelerada rotina de deslocamentos. Ignorar o que acontece nesses lugares de passagem é fragmentar a vida e selecionar somente as ações objetivas, é esquecer o processo e pensar somente no resultado final, como um professor que acredita que seus alunos são uma folha em branco prestes a ser preenchida tanto e somente o quanto seu mestre o desejar. É possível transformar esses não lugares em espaços singulares a nós, perceber como eles influem no que fui, estou sendo ou virei a ser, passar por eles como aventureiros desbravadores e não como sonâmbulos levados pelo impulso de chegar à geladeira.

Hernández (2009) aponta o "alfabetismo da cultura visual" como uma busca da percepção das imagens dentro das práticas sociais, da produção de significados ao invés da compreensão de respostas já pré-definidas: 
Quando faço referência a um alfabetismo da cultura visual, não apenas me refiro às formas alternativas de 'ler' as representações visuais, mas a uma reflexão crítica sobre como estas representações produzem formas de ver e visualizar posições e discursos sociais. De forma especial, a respeito das formas subjetivas de olhar o mundo e a si mesmo por parte dos visualizadores. (HERNÁNDEZ, 2009, p. 23)

É buscar conhecer o universo cotidiano além daquilo que nos é mostrado, concordando, discordando, apontando outras vias, mas nunca ignorando. Assim, podemos reavaliar nosso lugar, ou lugares, dentro do espaço que habitamos, nossas identificações que nunca se fazem de maneira acabada, transformando-se à medida que o espaço cotidiano também é transformado. Ideias e conceitos vão sendo formados e modificados durante toda a vida, tudo o que pensamos agora são compreensões marcadas por uma relação passada em nosso convívio social, cultural e econômico. "A mídia nos diz como devemos ocupar uma posição-de-sujeito particular - o adolescente 'esperto', o trabalhador em ascensão ou a mãe sensível" (SILVA, 2000, p.17) e é a maneira como avaliamos, dialogamos e negociamos com essas produções da cultura visual juntamente com as pessoas que as constróem e as difundem que tecerá nosso pensamento e visões de mundo.

\section{A arte na reinvenção do cotidiano educacional}

Vemos, hoje, o quanto se faz necessária uma revisão das metodologias utilizadas pelas escolas para trabalhar a arte com os educandos, considerando que a arte contemporânea se encontra cada vez mais próxima do público, ao passo que muitos professores ainda ignoram ou desconhecem as mudanças ocorridas no universo artístico. A exemplo disso, pode-se citar a ausência da arte pública nas produções desenvolvidas nas escolas, possibilidade artística existente há séculos e, pelo menos há quatro décadas, utilizada por artistas como uma maneira de aproximar a arte das pessoas. Essas ações perenes e/ou efêmeras pensadas para situações públicas, mesmo se inserindo no espaço cotidiano, ainda costumam ser ignoradas por muitos educadores, que optam por valorizar a construção de trabalhos em espaços fechados, limitados ao papel, lápis e mimese.

O estudo da arte pode se tornar muito mais significativo quando aproxima suas produções para uma realidade mais palpável ao educando, valorizando a riqueza de saberes pos- 
sibilitada pelas diferenças culturais. Assim, a competitividade presente na busca por melhores notas pode dar lugar à reciprocidade do aprender e ensinar, do aprender sobre si no mundo e não para acumular fragmentos de respostas prontas para perguntas imutáveis.

A ênfase na mimética compõe uma narrativa dominante que tende a homogeneizar a educação, estabelecendo padrões que necessitam obrigatoriamente ser seguidos para que a aprendizagem seja efetivada. Dialogar sobre o próprio espaço, não como cópia, mas como possíveis ambientes de criação, amplia a ideia de educação para além da escola, mostrando que a aprendizagem não se faz unicamente através do confinamento em salas fechadas, organizadas pelo ensino institucionalizado, mas que também se faz partindo daquilo que se vê, que se conhece e se toca no espaço externo.

Uma questão importante é o planejamento de um currículo flexível, capaz de abranger os diversos contextos dos educandos, adaptando o conteúdo, de forma que o estudante consiga sentir as ligações da arte estudada com a vida vivida. Steinberg (2004) explica que

geralmente o currículo escolar é organizado como uma seqüência contínua de experiências desenvolvidas como se as crianças aprendessem sobre o mundo na escola, num desenvolvimento progressivo (STEINBERG, 2004, p. 34).

Tal progressão não condiz com a realidade dispersa na qual estão inseridos, onde são levados por um fluxo ininterrupto de informações que quase nunca se completam e nem se expõem numa seqüência temporal única.

Os professores de arte poderiam pensar no desafio de transcender a linearidade dos currículos escolares, pois a compreensão do mundo pelos educandos se faz cada vez menos de forma linear. Lanier (apud TAVIN, 2003, p. 13) fala da necessidade de uma "revolução social" através do estudo de "filmes, televisão, da fotografia em revistas populares e design de interiores de lugares públicos", pois conteúdos que abordam questões cotidianas do educando possibilitam uma melhor construção de sentido, ao passo que partem de algo já familiar para a construção de novas relações de saber. Nesse sentido, o trabalho com arte pública na educação propõe fazer do espaço cotidiano um motivador de experiências artísticas que potencializem a pesquisa em arte como descoberta de si. Conhecer obras de artistas que atuam no espaço público instiga no educando não só o interesse pela arte atual, 
mas em encontrar sentidos para os lugares habitados, em entender que a produção em artes visuais vai além do saber mimético, mas está principalmente no pensar, no criar algo visual, não para embelezar, mas para discutir acerca do mundo e de seus lugares.

Uma educação pensada a partir de transgressões daquilo que se impôs por meio da tautologia busca vieses mesmo dentro de sistemas lineares, voltando a educação para uma realidade cotidiana de quem a vivencia e não àquela imposta por interesses maiores. É preciso estarmos conscientes que o papel da educação escolar não é formar artistas ou profissionais de qualquer área, mas mediar descobertas e invenções, para que os jovens se vejam capazes de fazê-las por si próprios na sociedade que ajudam a construir. Desse modo podemos traçar estratégias de ensino que motivem o educando a produzir com prazer de aprender, não para as instituições, mas para a própria vida.

\section{Entrecruzando diálogos com os entrevistados}

Com a realização de quatro entrevistas semi-estruturadas executadas ao longo do primeiro semestre de 2010 elaboro questões que problematizam as experiências dos entrevistados no que diz respeito a suas familiaridades com o ensino, a aprendizagem e a produção artística em arte pública.

Através da interpretação dos diálogos obtidos, busco perceber, na decupagem das entrevistas gravadas em áudio, aproximações possíveis entre as falas dos quatro entrevistados. Elaboro um cruzamento entre as respostas obtidas, a relação com alguns autores e meus apontamentos a partir dessas colocações, na busca de uma fluidez textual para a elaboração de sentidos que sintetizem a amplitude das respostas obtidas e ancorem as reflexões que proponho nesta pesquisa. Utilizo o texto em itálico nas citações diretas das entrevistas para que as mesmas não se confundam com as palavras dos autores referenciados.

Os entrevistados que colaboraram com este trabalho foram: um artista em formação que realiza intervenções em espaços abertos de Santa Maria; uma professora de artes visuais que atua há alguns anos na Educação Básica abordando a temática do grafite; um professor recém formado no curso de artes visuais que em seu estágio desenvolvera algumas questões de arte pública como complemento à temática de Histórias em Quadrinhos; e uma estudante do primeiro ano do Ensino Médio que experimentara a produção de intervenções em espaço público através das aulas desenvolvidas no ano anterior 
pelo professor entrevistado. Iniciando as entrevistas pela indagação de como cada um define "arte pública", surge nas falas a inquietação sobre como delimitar os espaços destinados à arte 'dita' como pública. Os entrevistados se auto-questionam se ela estaria limitada a locais abertos ou a qualquer espaço onde houvesse livre acesso ao público, a exemplo dos museus. É notável a polêmica que a terminologia "pública" provocara entre os entrevistados na discussão sobre o espaço da arte. $\mathrm{O}$ artista entrevistado classifica a arte pública não pela sua localização em espaços abertos, mas pelo acesso que qualquer indivíduo pode ter à arte, mesmo em lugares fechados. Já o professor define arte pública como uma produção que entra em contato direto com a população, abrangendo um público maior do que aquele que por iniciativa própria visita exposições em instituições fechadas como museus e galerias.

O museu, na concepção dos entrevistados, acaba se afastando da realidade do público, em um isolamento que muitas vezes assusta a grande camada da população que não foi educada a interessar-se por tais lugares, como se esses lugares de tamanha elitização não pertencessem a ela. Como diz o professor: "ela é pública num sentido prático, mas acaba que a compreensão dela não seja tão pública”. Um acesso que pode estar restrito pelo fato de certas pessoas não compreenderem o papel dessas instituições e não serem incentivadas a conhecê-las, estando, portanto, distantes de sua realidade.

O artista José Resende (2008, p. 46) defende que a arte não deixa de ser pública ou se torna menos pública quando mantida sobre propriedade privada, haja vista queseu caráter de 'bem público' permanece. Assim, para ele, não éa quantidade de pessoas que visualiza uma obra que classifica o quantoessa podeser privada ou não. Noentanto, osentrevistados colocam a educação em artes visuais como uma grande responsável pelo distanciamentodopúblicocomaarteinstitucionalizada, jáqueoseducandoscostumam receber pouquíssimo incentivo nas escolas para conhecer e freqüentar espaços culturais, tendo acesso a pequenas reproduções de pinturas e esculturas canônicas em livios, sem contextualizaçãocoma culturaatual.

$\mathrm{O}$ artista sustenta ainda que mesmo em obras instaladas em espaços abertos o mesmo distanciamento e incompreensão evidenciados em museus podem ocorrer nas ruas:

Então a mesma pessoa que não entende o que está sendo produzido dentro do MARGS² pode ser a mesma pessoa que não vai entender uma intervenção urbana. Então pra mim, isso é um problema da educação. A arte pública se tem acesso sem pagar. A arte no espaço público vai se aproximar do transeunte. E o problema da educação vai estar relacionado a qualquer obra. 
A busca pelo entendimento das obras expostas vem, muitas vezes, do interesse por compreender o papel da arte contemporânea, de entender que nem toda produção é feita para ser admirada ou compreendida de fato, que ela pode estar sendo exposta justamente para causar estranhamento. Essa aproximação dar-se-ia de forma mais fácil se o público se permitisse ser tocado por essas ações, a conhecer as produções dos artistas que habitam seus espaços, que interceptam seus caminhos, provocando afetos ou desafetos.

O professor acredita que, como ele, muita gente tem sua atenção voltada para a arte pública institucionalizada (os monumentos, as esculturas, o mural...) ao menos quando os veem pela primeira vez, mas para ele, o problema está na legitimação das novas linguagens, "às vezes nem mesmo o poder público aceita bem o fato de estar acontecendo uma intervenção".

A condição da obra enquanto 'pública' muitas vezes depende de interesses institucionais que acabam por colocar a arte como dependente de órgãos privados. Como explica Alves (2006):

Faz-se necessário lembrar que essa atribuição [arte pública] foi dada a uma determinada categoria de objetos artísticos sem que houvesse garantia de que tais obras estivessem situadas em um espaço que é efetivamente público, já que esse espaço, em última instância, é mediado pelas tensões e disputas dos diversos poderes que agem sobre ele. (ALVES, 2006, p. 20)

Essa discussão acerca da legitimação da arte pública não monumental, tanto pelos órgãos institucionalizados, como pelo público das ruas, se faz bastante presente nos diálogos de todos os entrevistados, assim, discutimos acerca das razões que levam o público a afastar-se ou aproximar-se desses trabalhos, haja vista que tais produções interceptam o cotidiano das pessoas que se deslocam pelos espaços das cidades, provocando reações e reinventando visões de lugares habitados.

A professora relata a reação das pessoas às produções feitas pelos educandos na escola:

Tem um momento que eles acham bonito, o conceito é bem assim: ou é bonito ou feio. Aí tem uns que acham mais agradável, acham que dá um colorido, dá um aspecto diferente pra escola, foge um pouco daquele muro branco tradicional de escola, traz uma vitalidade diferente. 
Essas impressões são dadas pelos pais e professores que circulam na escola, que valorizam o trabalho muito mais pela decoração da recepção do que pelas temáticas manifestadas pelos educandos. O trabalho, para grande parte das pessoas que ali circulam, precisa ser agradável ao olhar.

Oprofessor entrevistado, por sua vez, diz quea arte em espaço público, quando não usada para embelezamento, causa desconfiança do público, que se horroriza antes de saber quem são ou o que fazem essas pessoas que estão ali alterando seu cotidiano.

Parece haver uma sociedade que preza pela neutralidade visual da cidade, uma busca pela pureza, a qual muitas vezes é quebrada pela intervenção dos artistas. Segundo o artista entrevistado, a limpeza das paredes parece apresentar uma contradição aos problemas da sociedade:

as pessoas querem ver as paredes brancas, as pessoas gostam de ver os prédios limpos, as pessoas gostam de ver o mural do Amoretti sem $\mathrm{FPK}^{3}$, as pessoas querem ver as coisas limpas. Só que a questão é que a sociedade não é limpa, a sociedade não é pura, a sociedade tem erros, tem falhas, e quando as coisas começam a aparecer nas paredes é porque tá mostrando que a sociedade tem falhas.

Como sugere o artista, em determinadas situações, paredes brancas podem significar a impossibilidade de expressão pelos habitantes de determinado espaço. Paredes brancas simbolizam o espaço público como de qualquer um, há ausência de individualidades. $\mathrm{O}$ artista acredita que essas manifestações agridem porque mexem com as estruturas de uma civilização que preza pela repetição, onde a

ordem é uma espécie de compulsão à repetição que, quando um regulamento foi definitivamente estabelecido, decide quando, onde e como uma coisa deve ser feita, de modo que em toda circunstância semelhante não haja hesitação ou indecisão (BAUMAN, 1998, p.8).

Há um respeito a uma ordem imposta por uma minoria. As paredes brancas, na visão do artista, podem demonstrar o quanto a sociedade respeita a lei imposta pelo poder. As obras que se dizem públicas, mas que não consideram o público no momento de sua colocação nos espaços da rua são aquelas que provavelmente mais vão sofrer ataques de pichadores, que ao demarcar sua sigla, não representam somente a si, mas a todo 
um pensamento coletivo, acreditando na cidade como um patrimônio dos habitantes e não do poder público.

Durante os diálogos, proponho também aos entrevistados uma discussão sobre a relevância do ver e do fazer arte pelos educandos na elaboração de projetos em arte pública.

Para o artista entrevistado, é importante produzir e discutir sobre arte pública na escola porque muitos estudantes ainda crêem no conceito de que a arte é composta apenas de imagens paradas e isoladas. Com a produção nos espaços públicos, segundo ele, a pessoa tem a oportunidade de conhecer outros enfoques do fazer arte, ela "vai começar a reparar mais no cotidiano dela, as imagens que fazem parte do cotidiano dela. Eu acho que isso é importante pros alunos".

$\mathrm{O}$ fato de estar produzindo no espaço cotidiano, a meu ver, implica na necessidade da percepção desses lugares, na busca por aproximar essas percepções dos temas aos quais os educandos optam por pesquisar, ou mesmo, de descobrir possíveis temas a serem pesquisados a partir dessas observações. É um aguçar os sentidos para o próprio cotidiano.

Para a estudante, não foi a temática "arte pública" que despertou seu interesse pelas aulas de arte, mas a forma como foi trabalhada essa relação com o cotidiano, percebendo ligações entre as obras produzidas por artistas e a realidade do público ao qual as obras eram destinadas, essa abertura para a escolha de temáticas e materiais e o fato de estar explorando outros espaços além da sala de aula e do desenho em papel.

Ao produzir, o educando estará estudando não só o papel do artista contemporâneo, mas também o seu próprio papel como atuante naquele lugar, estará não só respondendo a questões impostas pelo professor, mas criando seus próprios questionamentos acerca de si e do cotidiano que busca ressignificar por meio de suas ações. Hernández (2000) aponta que

quando um estudante realiza uma atividade vinculada ao conhecimento artístico não só potencializa uma habilidade manual, desenvolve um dos sentidos (a audição, a visão, o tato) ou expande sua mente, mas também, e sobretudo, delineia e fortalece sua identidade em relação às capacidades de discernir, valorizar, interpretar, compreender, representar, imaginar, etc. o que lhe cerca e também a si mesmo. (HERNÁNDEZ, 200, p. 42)

Diante disso, os entrevistados apresentam, em seus diálogos, possibilidades educativas que percebem como viáveis, através do 
uso da arte pública, na ressignificação das experiências em arte e educação, ampliando espaços para produções que dialoguem com o cotidiano de quem faz e também de quem as visualiza.

O professor explica que, no início, houve um estranhamento dos educandos com as aulas que exigiam deles a criação e não a cópia de uma proposta já direcionada. Muitos estudantes apresentam dificuldade em 'criar' sem um direcionamento pré-estabelecido, preferindo ter a possibilidade de observar e seguir padrões que garantem o êxito dos trabalhos. É difícil enfrentar o desafio de ser ele próprio responsável pela direção e método de expressão em seu trabalho e, como descreve o professor, quando começaram a surgir ideias, muitas delas não eram executáveis, mas que aos poucos isso foi sendo constatado e modificado pelos estudantes à medida em que iam percebendo as dificuldades.

Um fato importante para o despertar do interesse nas aulas, segundo a educanda entrevistada, fora que a maioria das propostas de aula do professor estagiário foram trabalhos que envolviam mais de uma única pessoa, tanto na produção quanto na visualização e interação. $O$ trabalho em grupo tem o potencial de promover uma quebra ao individualismo da disputa por melhores notas, já que é necessária a cooperação de diversas pessoas para que os trabalhos se concretizem.

O produzir em espaços públicos motivou os educandos de ambos os professores entrevistados, no instante em que perceberam seus trabalhos ganhando significados além da importância numérica comumente estabelecida pela nota do professor, mas por ampliar essas pesquisas em interações com um público maior, que também acompanha e se envolve nas produções, pelo reconhecimento de si através da ação coletiva, gerando reflexões sobre a ocupação e significação dos espaços cotidianos.

\section{Inconclusões}

Tendo em mente meu objetivo inicial de perceber como a arte pública pode se constituir em possibilidade de atuação e ressignificação do espaço cotidiano no contexto arte/educacional, despertado por indagações sobre minha própria atuação como artista e educadora, este trabalho de conclusão de curso propiciou reflexões vindas de diferentes contextos, por pessoas diferentes que encontram como ponto de intersecção a aproximação, também feita por ângulos diversos, com a arte pública. O justapor das entrevistas aponta algumas possibilidades de respostas para as questões a que me propus discutir, 
tendo gerado um entrecruzar de ideias que se complementam, mas não se completam, haja vista que as conclusões partem das experiências de um pequeno grupo de pessoas. Inúmeras outras tecituras ainda podem ser acrescidas por aqueles que se propuserem a adentrar neste diálogo, compondo uma rede, sem início nem fim, tecida infinitamente pelas linhas que cada um vincula a ela.

Percebo que, dentre outras possibilidades, a arte pública pode ressignificar cotidianos quando ela própria é constituída do cotidiano para o qual é proposta, não como redundância, mas como algo a mais, que reforça conceitos, os contradiz ou os dessitua, direciona olhares e pensamentos não simplesmente para a obra, mas para si a partir do que a obra propõe.

A realização de trabalhos artísticos no espaço cotidiano proporciona ao educando um tipo de experimentação que desafia suas potencialidades de criação, no momento em que o mesmo necessita conhecer o espaço e o material sobre os quais propõe desenvolver seu trabalho, deixando de somente conhecer obras de arte, mas passando a conhecer a si e ao seu próprio espaço.

Esta pesquisa demonstra que é possível promover fugas às paredes institucionais, desde que percebida a riqueza de recursos disponibilizados pela própria cidade, tanto pelas produções artísticas quanto pelas demais visualidades presentes nas praças, ruas ou mídia publicitária, a fim de construir problematizações, que nas suas incompletudes enquanto respostas, gerem imensuráveis possibilidades de produção de conhecimento.

\section{Referências bibliográficas}

ALVES, José Francisco. Transformações do Espaço Público. Porto Alegre: Fundação Bienal de Artes Visuais do Mercosul, 2006.

BAUMAN, Zygmunt. O mal-estar da Pós-Modernidade. Rio de Janeiro: Jorge Zahar Ed., 1998.

CANTON, Katia. Espaço e Lugar. São Paulo: Editora WMF Martins Fontes, 2009.

CARVALHO, Ana Maria Albani de. Instalação como problemática artística contemporânea. In CATTANI, Icleia Borsa. (Org.) Mestiçagens na arte contemporânea. Porto Alegre: Editora da UFRGS, 2007. p. 103 - 123.

DOBERTI, María Paula. Arte Público y Memoria: Imágenes retentivas y efímeras en las calles de Buenos Aires. In Seminario Internacional sobre arte público en Latinoamérica, 1, 2009, Buenos Aires. Anais. Buenos Aires: Instituto de Teo- 
ría e Historia del Arte 'Julio E. Payró', 2009. CD-ROM.

ECO, Umberto. Obra Aberta. São Paulo: Editora Perspectiva, 2003.

FOUCAULT, Michel. De outros Espaços. Conferência no Cercle d'Études Architecturales, em 14 de março de 1967. Tradução por Pedro Moura. Disponível em <http://saladobradica.blogspot.com $>$. Acessado em 22 de novembro de 2009.

HERNÁNDEZ, Fernando. Cultura visual, mudança educativa e projeto de trabalho. São Paulo: Editora Artes Médicas Sul Ltda., 2000. Da Alfabetização Visual ao Alfabetismo da Cultura Visual. In MARTINS, Raimundo; TOURINHO, Irene. (Orgs.) Educação da Cultura Visual - narrativas de ensino e pesquisa. Santa Maria: Editora da UFSM, 2009. p. 189 - 212.

PEIXOTO, Nelson Brissac. Paisagens Urbanas. $3^{\text {a }}$ Ed. São Paulo: Editora Senac, 2003.

RESENDE, José. O que seria uma arte pública? In José Francisco Alves (org.) Experiências em Arte Pública: memória e atualidade. Porto Alegre: Artfolio e Editora da Cidade, 2008. p. 46 - 53.

SARAMAGO, José. O Conto da Ilha Desconhecida. 14를 reimpressão. São Paulo: Companhia das Letras, 2003.

SILVA, Fernando Pedro da. Arte Pública: diálogo com as comunidades. Belo Horizonte: Editora C/Arte, 2005.

SILVA; Tomaz Tadeu da. Identidade e diferença: a perspectiva dos estudos culturais. Petrópolis: Vozes, 2000.

STEINBERG, Shirley R.; KINCHELOE, Joe L. Cultura Infantil: a construção corporativa da infância. Rio de Janeiro: Civilização Brasileira, 2004.

TAVIN, Kevin M. Antecedentes críticos da cultura visual na arte educação nos Estados Unidos. In MARTINS, Raimundo (Org.). Visualidade e Educação. Goiânia: FUNAPE, 2008. p. 11 - 23. 
NOTAS

1. Coletivo formado pelos artistas Andressa Argenta, Fábio Purper Machado, Francieli Garlet e Tamiris Vaz. http://des-esperar.blogspot.com

2. Museu de Arte do Rio Grande do Sul, Porto Alegre, RS.

3. Sigla de um grupo anônimo de pichadores de Santa Maria que interviu, dentre vários outros lugares da cidade, em um mural do artista e professor Juan Amoretti, na UFSM.

Recebido em: 30/o8/10

Aceito em: 01/10/10

\section{TAMIRIS VAZ \\ tamirisvaz87@gmail.com}

Acadêmica do curso de Licenciatura em Artes Visuais, UFSM; bolsista do Programa Pibid em projeto de arte pública na escola; membro do GEPAEC (Grupo de Pesquisa em Arte, Educação e Cultura); integrante do Grupo de Ações Artísticas (Des)esperar na cidade de Santa Maria - RS, onde realiza intervenções escultóricas em espaços abertos e fechados.

\section{VIVIANE DIEHL}

Mestre em Educação pela UPF. Docente do curso de Artes Visuais da UFSM, Arte-educadora e assessora do Curso de Artes Visuais da UNOESC-SC, coordenadora do Projeto de Alfabetização estético-cultural. Artista Plástica do Atelier Vivie Diehl. 